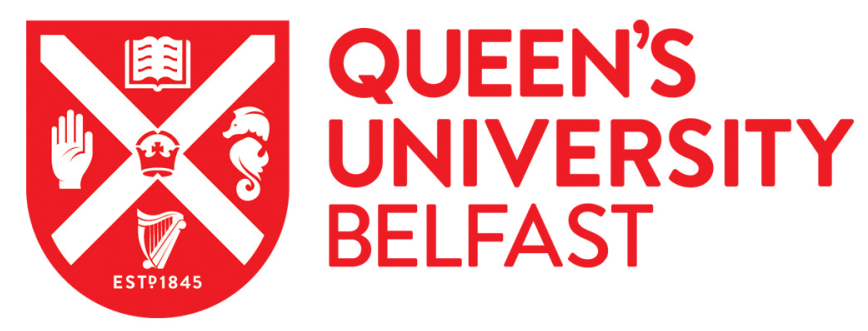

\title{
Improved culture detection of Staphylococcus aureus from sputum of patients with cystic fibrosis (CF)
}

Wen, H., Stirling, J., McCaughan, J., Schock, B., Downey, D. G., Ennis, M., \& Moore, J. E. (2019). Improved culture detection of Staphylococcus aureus from sputum of patients with cystic fibrosis (CF). Journal of Clinical Pathology, jclinpath-2019-206059. https://doi.org/10.1136/jclinpath-2019-206059

Published in:

Journal of Clinical Pathology

Document Version:

Peer reviewed version

Queen's University Belfast - Research Portal:

Link to publication record in Queen's University Belfast Research Portal

Publisher rights

Copyright 2019 BMJ. This work is made available online in accordance with the publisher's policies. Please refer to any applicable terms of use of the publisher.

\section{General rights}

Copyright for the publications made accessible via the Queen's University Belfast Research Portal is retained by the author(s) and / or other copyright owners and it is a condition of accessing these publications that users recognise and abide by the legal requirements associated with these rights.

Take down policy

The Research Portal is Queen's institutional repository that provides access to Queen's research output. Every effort has been made to ensure that content in the Research Portal does not infringe any person's rights, or applicable UK laws. If you discover content in the Research Portal that you believe breaches copyright or violates any law, please contact openaccess@qub.ac.uk. 


\section{* Corresponding author:}

Professor John E. Moore,

Northern Ireland Public Health Laboratory,

Department of Bacteriology,

Belfast City Hospital,

Belfast BT9 7AD,

Northern Ireland,

United Kingdom.
Tel:
+44 (28) 90263554
Fax:
+44 (28) 90263991
E-mail:
jemoore@niphl.dnet.co.uk 
Staphylococcus aureus (SA) is a facultative anaerobic Gram-positive coccus, found in $30 \%$ to $50 \%$ of the healthy adult population.[1] It is considered to be a commensal organism of humans and around 20\% of individuals are 'persistent carriers'. The organism resides most commonly in the anterior nares, where there is a relative absence of immunological defences and colonisation is achieved through bacterial adherence to the surface membrane of the host cells.[2] Other common sites include the axillae, vagina and pharynx. SA is responsible for a diverse range of diseases; from skin and soft tissue infection, pneumonia and gastrointestinal (GI) poisoning, to fatal conditions of bacteraemia, endocarditis, sepsis and toxic shock syndrome.[1] Within cystic fibrosis (CF), SA is the most commonly isolated organism, where more than half of US individuals had at least one culture positive for methicillin sensitive SA in 2017 and its occurrence, was highest in those younger than 10.[3] Controversies remain ongoing regarding its clinical significance in early and adult lung pathology, as well as optimal treatments regimens in these populations. In a seminal review by Wong and colleagues,[4] the authors highlighted the need for further investigations to help understand (i). the early host immune response that enables SA to reside within the CF lung, (ii) to determine if there are organism specific factors that are associated with CF lung disease and (iii) to clarify the utility of anti-staphylococcal antibiotic prophylaxis and/or eradication in the treatment of this patient population. Therefore, robust and reliable methods for the laboratory detection of SA are needed to support the evidence for SA involvement in lung disease. It was the aim of this study to (i). compare the optimum agar to recover SA from CF sputum and (ii). compare selective enrichment versus non-enrichment for the recovery of SA from CF sputa. 


\section{Staphylococcus aureus}

72

Freshly expectorated sputum was obtained from CF patients $(n=47)$ and processed with , sputasol (SR0233, Oxoid Ltd., UK), as previously described.[5] Five agar media were compared by reconstituting in accordance with the manufacturers' instructions, including (i) nutrient agar (CM003), (ii) Columbia blood agar (CM0331), supplemented with 5\% (v/v) defibrinated horse blood, (iii). colomycin agar [Columbia blood agar base (CM0331) 39g/L; mannitol 10g/L; $\mathrm{NaCl} 25 \mathrm{~g} / \mathrm{L}$, bromocresol purple (1.6 [w/v]\% solution) $4 \mathrm{~mL} / \mathrm{L}$, colomycin (1 Million I.U. dissolved in $10 \mathrm{~mL}$ of Sterile Water) $0.5 \mathrm{~mL} / \mathrm{L}$, (iv). Baird-Parker agar (Oxoid CM1127) and (v) Brilliance Staph agar (LIP W11494). Lysed CF sputum (10 $\mu$ l) was inoculated onto each plate and incubated aerobically at $37^{\circ} \mathrm{C}$ for $48 \mathrm{~h}$, prior to examination of plates for the typical presence of SA. Presumptive SA colonies were subsequently subcultured and confirmation testing. Two positive SA controls were also included, namely NCTC 6571 WDCM 00035 and a well-characterised CF clinical SA isolate, NISA1.

\section{(ii) Comparison of selective enrichment and non-enrichment for the detection of}

\section{Staphylococcus aureus}

Freshly expectorated sputum was obtained from CF patients $(n=19)$ and processed with , sputasol (SR0233, Oxoid Ltd., UK), as previously described .[5] For the non-enrichment arm of the study, Baird-Parker agar (Oxoid CM1127) and Brilliance Staph agar (LIP W11494) were inoculated with lysed CF sputum $(10 \mu \mathrm{L})$ and incubated aerobically at $37^{\circ} \mathrm{C}$ for $48 \mathrm{~h}$. For the selective enrichment arm of the study, mannitol salt broth (MSB) was prepared as follows:-nutrient broth No.2 Base (Oxoid CM0085) 25g/L, supplemented with mannitol $(10 \mathrm{~g} / \mathrm{L})$ and $\mathrm{NaCl}(70 \mathrm{~g} / \mathrm{L})$. MSB was dispensed in $10 \mathrm{~mL}$ amounts into disposable universal bottles, capped and autoclaved at $121^{\circ} \mathrm{C} / 20 \mathrm{~min}$. 
CF sputum $(500 \mu \mathrm{L})$ was inoculated into MSB $(10 \mathrm{~mL})$ and incubated at $37^{\circ} \mathrm{C}$ for 48 hours. Following this period, $10 \mu \mathrm{L}$ was inoculated onto Baird-Parker agar (Oxoid CM1127) and Brilliance Staph agar (LIP W11494) and incubated as above. Two positive SA controls were also included in this study, as detailed above. All isolates examined were methicillinsensitive Staphylococcus aureus (MSSA).

Isolation of SA varied depending on agar type. Highest recovery of SA was from BairdParker agar $(24 / 47 ; 51.1 \%)>$ Brilliance Staph agar $(23 / 47 ; 48.9 \%)>$ colomycin agar $(6 / 47$; $12.8 \%)>$ nutrient agar $(1 / 47 ; 2.1 \%)$, Columbia Blood agar $(1 / 47 ; 2.1 \%)$. All five media successfully grew both SA control organisms, namely WDCM 00035 \& NISA1. Selective enrichment recovered more SA from CF sputum on Baird Parker agar (6 SA positives/19 CF sputa v 3/19 for non-enrichment) and on Brillance Staph agar (6/19 v 4/19 for nonenrichment).

This study showed that both Baird Parker agar and Brilliance Staph agar were the best agars for recovery SA from CF sputum, with the others, namely nutrient agar, Columbia blood agar and colomycin agar, being poor at isolating SA $(<10 \%$ recovery). This was probably due the overgrowth of SA on these media with contaminating organisms from the rich diversity of bacteria found in CF sputum. Current guidelines for the isolation of SA from CF sputum include (i). UK CF Trust Laboratory Standards for Processing Microbiological Samples from People with Cystic Fibrosis [6] (ii). Public Health England's UK Standards for Microbiology Investigations: Investigation of bronchoalveolar lavage, sputum and associated specimens [7] and (iii). the US Cumitech protocol.[8] All of these methods recommend inclusion of mannitol salt agar/chromogenic agar for the isolation of SA from CF respiratory specimens. However, none of these include a selective enrichment step, prior to selective plating. This 
current study has shown that in addition to the plating stage with selective/differential agar,

121 inclusion of a selective enrichment step helped increase the number of positive SA

122 specimens, compared to not having incorporated an enrichment stage. Selectivity for SA was

123 enhanced by including the MSB enrichment step, as it added a preliminary selection phase

124 for SA based on high salt concentration $[7.5 \% \mathrm{w} / \mathrm{v}]$, followed by the selective components of

125 either Baird Parker agar or Brilliance Staph chromogenic agar. Higher recovery rates were

126 seen when using enrichment prior to selective plating. We believe that the reason for the

127 difference is due to bacterial numbers, namely that enrichment was able to allow for the

128 proliferation of small numbers in CF sputum to detectable levels that were able to be seen on

129 subsequent selective culture.

130

131 Where SA is present in smaller numbers, i.e. during early colonisation/infection or during

132 intermittent infection, we therefore endorse the isolation method, as detailed in Figure 1, for

133 the optimal recovery of SA from CF sputum. 
138 The authors wish to acknowledge with thanks Mr Alan Murphy, Northern Ireland Public

139 Health Laboratory, Belfast City Hospital, for his help in preparing all media described in this 140 study.

141

142 COMPETING INTERESTS: None declared. 
1. Lowy FD. Staphylococcus aureus Infections. N Engl J Med, 1998;339:520-32.

2. Kluytmans J, Van Belkum A, Verbrugh H. Nasal carriage of Staphylococcus aureus: epidemiology, underlying mechanisms, and associated risks. Clin Microbiol Rev 1997;10:505-20.

152

3. Anon. 2017 Patient Registry Annual Data Report. Cystic Fibrosis Foundation, Bethesda, USA. 2018., pp34.

4. Wong JK, Ranganathan SC, Hart E et al. Staphylococcus aureus in early cystic fibrosis lung disease. Pediatr Pulmonol 2013;48:1151-9.

5. McClean M, Stanley T, Goldsmith CE, et al. Determination of optimum incubation time for release of bacteria from sputum of patients with cystic fibrosis using dithiothreitol (sputasol). Br J Biomed Sci 2010;67:89-91.

162

6. Anon. Laboratory standards for processing microbiological samples from people with cystic fibrosis. Report of the UK Cystic Fibrosis Trust Microbiology Laboratory Standards Working Group. 2010. UK Cystic Fibrosis Trust, London, UK.

8. Gilligan PH, Kiska DL, Appleman MD. Cystic Fibrosis Microbiology. Cumitech: Cumulative Techniques and Procedures in Clinical Microbiology. 2006;43, 1-36, American 
Figure 1: Improved methodology for the isolation of Staphylococcus aureus from the sputum of patients with cystic fibrosis $(\mathrm{CF})$

181

182

183 